JOURNAL DE PHYSIQUE

Colloque C10, supplément au $\mathrm{n}^{\circ} 12$, Tome 46 , décembre 1985 page $\mathrm{Cl0}-827$

\title{
ULTRASONIC ATTENUATION NONDESTRUCTIVE MATERIALS CHARACTERIZATION
}

\author{
R.E. GREEN, Jr. \\ Center for Nondestructive Evaluation, The Johns Hopkins \\ University, Baltimore, MD 21218, U.S.A.
}

\begin{abstract}
Resume - Nous présentons une revue de l'etat actuel de l'utilisation de l'attenuation des ultrasons comme technique non-destructive pour la caractérisation de materiaux. Des examples vont être présentes pour illustrer comment le cholx approprié des parametres experimentaux permet l'utilisation des mesures d'at tenuation d'ultrasons pour 1'6tude des grosseur de grains, deformation plastique, et concentration d'1mpuretés. Nous allons commenter les nouvelles techniques utilisant la generation et la détection de faisceaux de laser qui permettent l'emplo1 des mesures d'attenuation d'ultrasons á de cas non-accessibles aux methodes plus conventionelles et elargissant, par consequent l'utilité pratique des mesures d'attenuation ultrasonique á la caracterisation non-destructive des matèrlaux.
\end{abstract}

Abstract - The present paper will present an overview of the current state-of-the-art of the use of ultrasonic attenuation as a nondestructive technique for materials characterization. Bxamples will be given as to how proper cholce of experimental parameters permit ultrasonic attenuation measurements to be used to study grain size, plastic deformation, and Impurity concentration. Some oomments will be made as to new techniques using laser beam generation and detection which afford the possibility of making ultrasonic attenuation measurements not possible by more conventional means and thereby expanding the practical usefulness of ultrasonic attenuation nondestructive materials characterization.

\section{I - INTRODUCTION}

The use of ultrasonic waves as nondestructive probes has as a prerequisite the careful documentation of the propagational characteristics of the uItrasonic waves themselves $/ 1 \%$. Since in nondestructive evaluation appl lcations it is not desirable for the ultrasonic waves to alter the material through which they pass, it is necessary to work with very low amplitude waves, which are normally regarded to obey Inear elasticity theory. The ultrasonic waves generated experimentally behave as inear elastio waves in many of their propagational characteristics, but in other characteristios associated with wave interactions, distortion, harmonio generation, and energy loss mechanisms, their behavior is nonl inear and in some respects even nonelastic. Although most practical uses of ultrasonics are applied to solid materials which are polycrystalline aggregates and therefore assumed to be isotroplc, with real orystalline solids the condition of ideal isotropy is extremely difficult if not impossible to attain. Therefore, most real polycrystalline aggregates possess a "texture" which strongly influences the mechanical properties of the anisotropic material including ultrasonic wave propagation.

Al though many Investigators draw a close analogy between electromagnetic wave propagation and elastic wave propagation in solid materials, great caution should be exercised in doing so. The behavior of anisotropic materials with respect to propagation of elastic waves is much more complioated than is the case for propagation of electromagnetic waves, since the material constitutive equations required to properly describe elastic waves are of higher order tensor rank than those required to describe electromagnetic waves $/ 2 /$. 
II - TLTRASONIC ATTENOTION

For all real solids, the assumption of pure elasticity is only an approximation, since all real ultrasonic waves are attenueted as they propagate. Ultrasonic attenuation measurements serve as a very sensitive indicator of internal loss mechanisms caused by microstructures and miorostructural alterations in the material /3/. Figure 1 shows the experimental results of $\mathrm{KlIm}$ an and Stephenson /4/, who measured longitudinal ultrasonic wave attenuation as a function of grain size for both laboratory and commercially produced plates of plain carbon-manganese

Perrite-pearlite steel. In order to obtain the data shown In FIg. 1 measurements were made at both 5 and $10 \mathrm{MHz}$. It is evident that for this material the higher frequency established a much more definitive relationship between attenuation and metallographically measured grain size. The usefulness of such measurements for industrial quality control is self-evident.

Buxbaum and Green /5/ measured ultrasonic attenuation as a function of location along thlok section weldments of titanium alloys. Not only was a dramatic decrease in attenuation observed as the transducer crossed the weld region, but marked increases in attenuation were observed on each side of the weld clearly delineating the heat affected zones. In companion work, the ultrasonic attenuation of $2.25 \mathrm{MHz}$ longitudinal waves was measured as a function of oxygen content in titanium specimens possessing oxygen levels of $0.07,0.14,0.20 .0 .24$ abd 0.29 percent by weight. Figure 2 shows the results, proving that such measurements provide a slmple technique for monttoring the oxygen content in these materials.

Sachse and Green $/ 6 /$ conducted experiments which 1llustrate the extreme sensitivity of ultrasonic attenuation measurements to dislocation motion and dislocation-point defect interactions. Figure 3 shows the results of an experiment in which an aluminum crystal, which had prevlously been loaded to a plastic load of $180 \mathrm{~kg}$, was reloaded to $60 \mathrm{~kg}$ and maintained at this load for one minute, unloaded to $45 \mathrm{~kg}$ and. maintained for one minute, unloaded to $30 \mathrm{~kg}$ and maintained for one minute, unloaded to $15 \mathrm{~kg}$ and maintained for one minute, and then unloaded completely. Opon subsequent reloading to $70 \mathrm{~kg}$ and unloading, the ultrasonic attenuation displayed dips at those load values which had been maintained for a short time during the previous cycle. Note that even though the attenuation nremembered" the discontinuous nature of the first load-unload cycle, the load-unload curve (or equivalently the stress-strain curve) gave no Indication of 1t. The observed results were attributed to the plnning of dislocation loops by point defects which were preferentially located at the position they occupled when the load was maintained constant for the one minute intervals. Upon reloading, these point defects pinned the dislocation loops again when the dislocations arrived at the location of the defects thus causing the dips in attenuation. These results show that ultrasonic attenuation measurements are sensitive to migration of point defects and their interaction with disloostions.

In the event that the wave amplitude is increased to sufficiently large values effects may arise, which can manifest themselves both as nonlinear elastic behavior /1/ or more drastically as plastic deformation of the insonated material. Mignogna and Green /7/ developed a multiparameter experimental system which, for the first time, permitted simultaneous measurement of sufficient quantitites to test all of the proposed mechanisms for the influence of high-power ultrasound on the mechanical properties of metal specimens. Pigure 4 shows a set of typlcal data obtained frcen an aluminum single crystal specimen subjected to high-power insonetion at $20 \mathrm{kHz}$. The Insonation was applied at a constant power level for different time pertods: I =. $0.03 \mathrm{sec}$, II $=0.63 \mathrm{sec}$, III $=1.23 \mathrm{sec}$, IV $=1.83 \mathrm{sec}, V=2.43 \mathrm{sec}$, and VI $=3.63$ sec. Depicted are change in specimen length, relative change in low-power nondestructive ultrasonic velocity and change in low-power ultrasonic attenuation as a function of time. The changes in low-power ultrasonic attenuation indicate that high-power ultrasound is capable of causing large scale dislocation motion and the resulting plastic deformation. 


\section{III - LASER GENERATION LASER DETECTION OF OLTRASOUND}

As early as 1963, White /8/ reported the generation of elastic waves in solid materials by transient surface heating and research has continued in this area up to the present time /9-17/. Although three different mechanisms have been proposed to account for the generation of ultrasonic waves by the impact of pulsed laser beams, namely radiation pressure, ablation, and thermoelasticity, the thermoelastic process is the only process which is truly nondestructive and still capable of generating an ultrasonic wave of sufficient amplitude for nondestructive evaluation purposes. Figure 5, taken from the work of Rosen /17/ shows a schematic illustration of a laser beam generation and dual laser beam interferometric detection system used to make non-contact measurements of ultrasonic waves in surface layers of metallic specimens which had been microstructurally modified by electron beam or high-power laser irradiation to either form an amorphous layer on the crystalline bulk, to produce different layers of transformed phases, or to induce case hardening of steel components.

Although a number of Investigators have reported both generation and detection of ultrasonic waves in solid materials using laser beams, only two investigations have been conducted using low-power laser beams. This is especially important for many non-contact nondestructive evaluation applications where portability and power Iimitations are a necessity. In 1983, Dewhurst /13/ constructed a hand-held Iaser generator of ultrasonic pulses based on components taken from a laser range $f$ inding device. The optical output was sufficient to generate both surface and bulk ultrasonic waves with an aluminum specimen. Nost recently, Bourkof $f$ and Palmer /16/ have succeeded in generating ultrasonic pulses in metals and composite materials using a low-energy tunable dye laser. The ultrasonic waveforms were detected optically with a laser Interferometer having improved signal-to-noise ratio and an electronic control system, which enables it to bo operated near common low frequency nolse sources. The overall sensitivity is about $50 \mathrm{pm}$ over a $10 \mathrm{MHz}$ bandwidth. This work has shown that it is entirely feasible to use a portable laser generation laser detection system for non-contact characterization of materials.

Another technique of increasing importance for nondestructive evaluation of materials is thermal wave imaging. As initially developed this technique was called photoacoustic spectroscopy and consists of laser beam scanning of a test object placed in a closed gas-filled container. This scanning causes changes in the gas pressure in direct proportion to thermal property changes in the surface layers of the test object. Recording of the pressure changes as a function of position of the laser pump beam permits imaging of surface and sub-surface microstructural features and defects in the test object. More recent developments have permitted elimination of the gas-filled container by use of a second probe laser beam, which either detects surface displacements of the test object due to localized thermal expansion or changes in the refract1ve index of the air just above the sample surface. Figure 6 1llustrates the way this "mirage effect" caused by the pump laser beam interacting with the test object causes deflections of the probe laser beam transversing the Index of refraction altered region.

Another modification of this technique uses a chopped electron beam in a scanning electron microscope to exolte elastic and thermal waves at the top surface of the test specimen. The propagation of these waves through the test specimen is modified by the mechanical and thermal characteristios of the material inhomogeneities through which they pass. These modifled waves are detected by a plezoelectrio crystal coupled to the bottom surface of the test specimen. By displaying and recording the output of the plezoelectrio orystal as a function of position of the scannins eleotron beam an "electronmacoustic" Image of the test specimen can be obtained. Alteration of the energy of the electron beam and chopping frequency permits different layers in the test specimen to be imaged as desired. Figure 7 compares a standard scanning eleotron image of an unetched sheet of polyorystalline aluminum with an electron-acoustic image of the same region of the test specimen. Is can be seen, the electron-acoustic Image clearly reveals the grain structure not detected by the econdary electron Image. 


\section{IV - CONCLUSIONS}

In order to properly use ultrasonic attenuation for nondestructive materials characterization it is extremely important to carefuliy document and understand the propagational characteristics of the ultrasonic waves themselves in the specific materials to be examined. Once this is done, proper choice of experimental parameters permits ultrasonic attenuation measurements to be used to study a great variety of material microstructures and associated mechanical properties. New techniques using laser beam generation and detection of ultrasound afford the possibility of making ultrasonic attenuation measurements not possible by more conventional means and thereby expanding the practical usefulness of ultrasonic attenuation nondestructive materials characterization.

\section{RERERENCES}

/1/ Green, R.E., Jr., Ultrasonic Investigation of Mechantcal Properties. Vol. III Ireatise on Materials Science and Technology, Academic Press, New York (1973).

/2/ Henneke, E.G., II and Green, R.E., Jr., Light-Wave/Elastic-Wave Analogies in Crystals, J. Acoust. Soc. Amer. 45, 1367-1373 (1969).

/3/ Green, R.E. Jr., Effect of Metallic Microstructure on Ultrasonic Attenuation, in Nondestructive Evaluation: Microstructural Characterization and Rel iability

Strategies, O. Buck and S.M. Wolf (eds.), The Metallurgical Society of AIME, Warrendale, PA, (1981) pp. 115-132.

/4/ Klinman, R. and Stephenson, E., Relation Between Mechanical Properties, Grain Size, and Ultrasonic Attenuation in Plain Carbon Steel, Research Department, Homer Research Laboratory, Bethlehem Steel Corporation, Bethlehem, PA (1980).

/5/ Buxbaum, S.R. and Green, R.E., Jr., Ultrasonic Characterization of Titanium 6211 Weldments, in Nondestructive Methods for Materlal Property Determination, C.L. Ruud and R.E. Green, Jr. (eds.), Plenum Press, NY (1984).

16/ Sachse, W. and Green, R.E. Jr., Experimental Study of the Orientation Dependence of Dislocation Damping in Aluminum Crystals, Trans. Metallurgical Soc. AIME 242, 2185-2190 (1968).

/7/ Mignogna, R.B. and Green, R.E., Jr., Multiparameter System for Investigation of the Effects of High-Power Ultrasound on Metals, Rev. Sei. Instrum. 5e, 1274-1277 (1979).

/8/ White, R.M., Generation of Elastic Waves by Transient Surface Heating, J. Appl. Phys. 34, 3559-3567 (1963).

/9/ Bondarenko, A.N., Drobat, Yu. B., and Kruglov, S.V., Optical Excitation and Detection of Nanosecond Acoustic Pulses in Nondestructive Testing, Sov let J. NDT 12, 655-658 (1976).

/10/ Ledbetter, H.M. and Moulder, J.C., Laser-Induced Rayleigh Waves in Aluminum, J. Acoust. Soc. Amer. $65,840-842$ (1979).

111/ Calder, C.A. and Wilcox, W.W., Non-Contact Material Testing Using Laser Energy Deposition and Interferometry, Mater. Eval. 38, 86-91 (1980).

112/ Wellman, R.L., Laser System for the Detection of Flaws in Solıd, Harry Diamond Laboratories, Report No. HDL-TR-1902 (1980).

/13/ Dewhurst, R.J., A Hand-Held Laser-Generator of Ultrasonic Pulses, NDT Communications 1, 93-103 (1983). 
/14/ Rudd, M.J. and Doughty, J.A., Laser Generation of Ultrasound, Naval Air Development Center, Report No. NADC-81067-60 (1983).

/15/ Alndow, A.M., Dewhurst, R.J., Palmer, S.B., and Scruby, C.B., Laser-Based Non-Destructive Testing Techniques for the Ultrasonic Characterization of Subsurface Flaws, NDT International 17, 329-335 (1984).

/16/ Bourkoff, E. and Palmer, C.H., Low-Energy Optical Generation and Detection of Acoustic Pulses in Metals and Nonmetals, Appl. Phys. Lett. 46, 143-145 (1985).

/17/ Rosen, M., Analytical Ultrasonics for Characterization of Metaliurgical Microstructures and Transformations, to be published in the Proceedings of the Analytical Ultrasonics in Materials Research and Testing Conference, NASA Lewis Research Center, Cleveland, OH (November 1984).

/18/ Aamodt, L.C. and Murphy, J.C., Thermal Effects in Photothermal Spectroscopy and Photothermal Imaging, J. Appl. Phys. 54, 581-591 (1953).

/19/ Maclachlan, J.W., Murphy, J.C., Givens, R.B, and Aamodt, L.D., Microstructure Characterization by Thermal Wave Imaging, to be published in Proceedings of In-Process Nondestructive Characterination and Process Control Symposium, ASM Metals Congress, Detroit, Michigan (1984), American Society for Metals, Metals Park, OHs (1985).

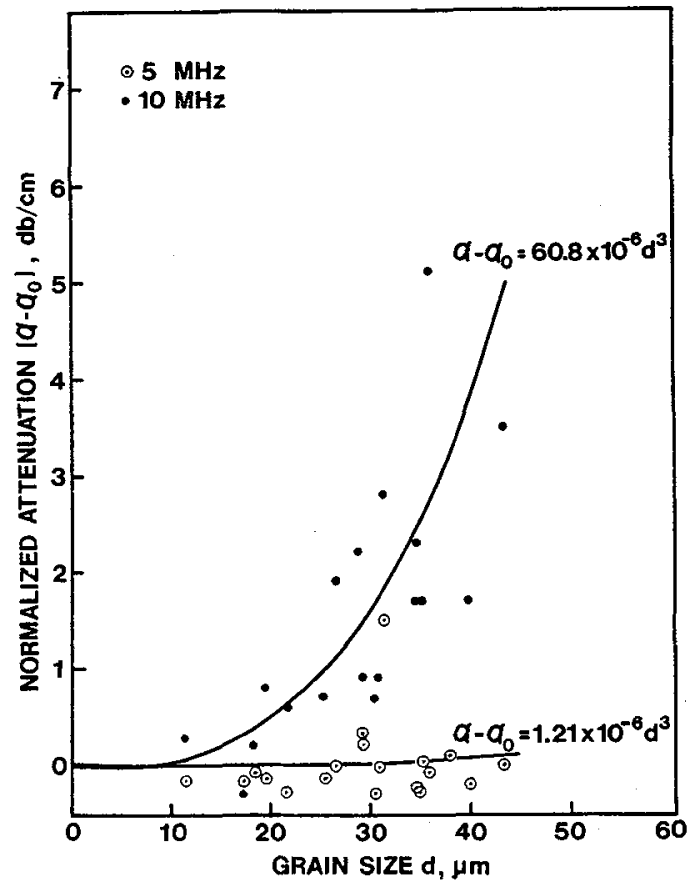

F1g. 1 - Longitudinal ultrasonic wave attenuation versus grain size for laboratory produced steel plate [4]. 


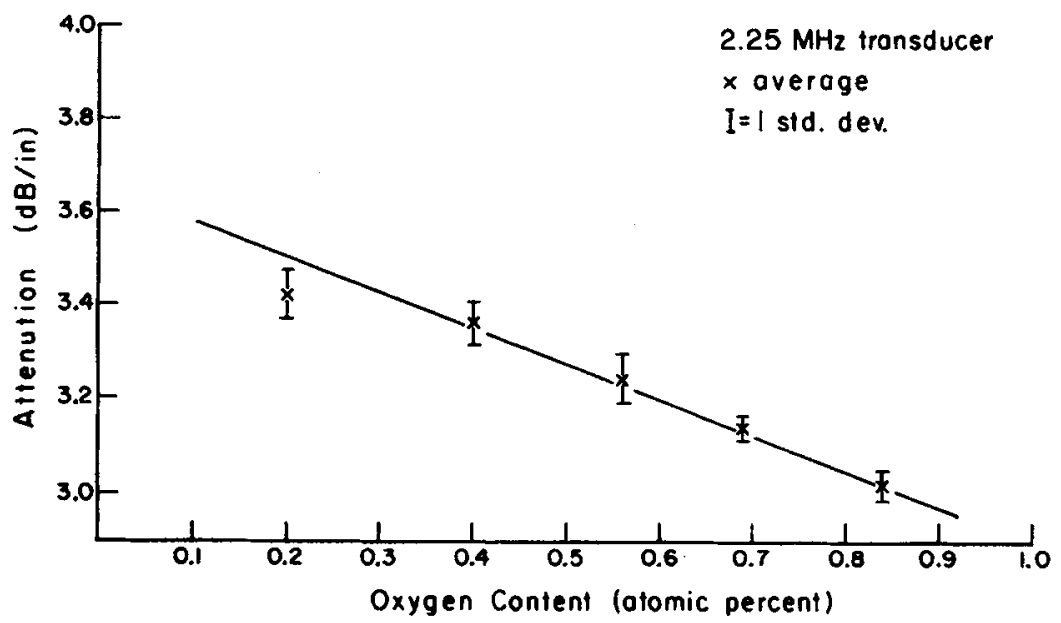

F1g. 2 - Ultrasonic attenuation as a function of oxygen content for a titanium alloy [5].

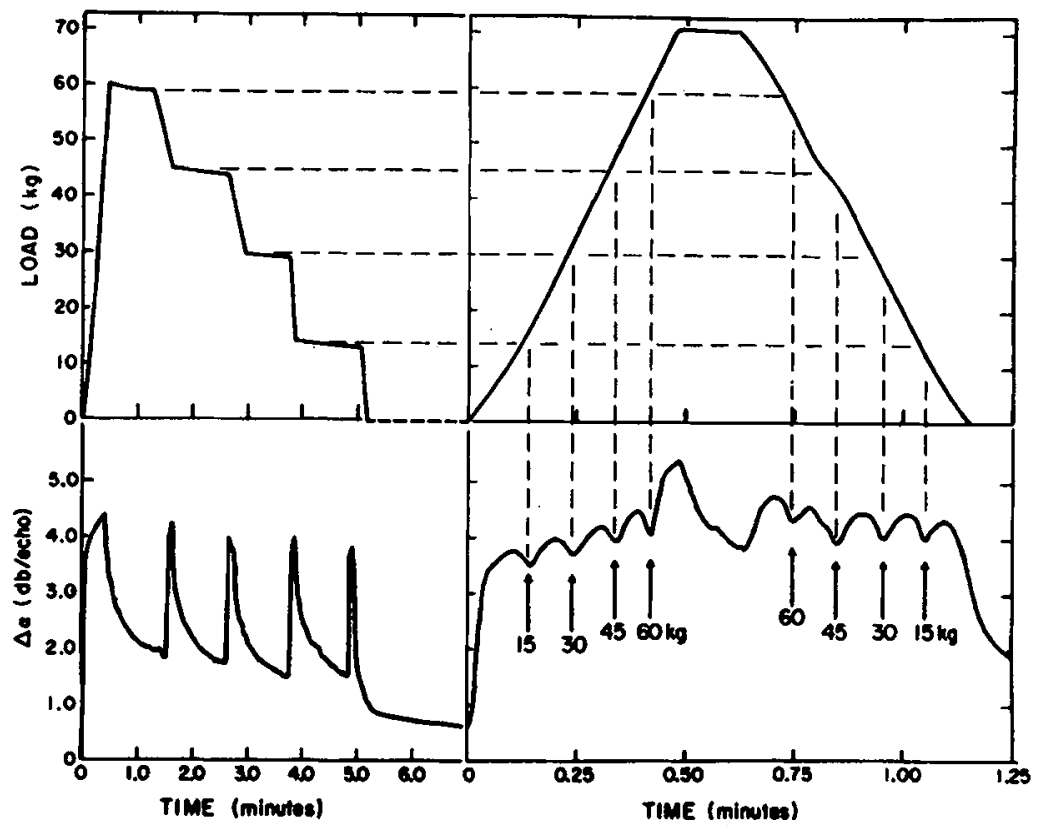

Fig. 3 - Load versus time and ultrasonic attenuation change versus time plots obtained during a load-hold-unload-hold sequence (left), followed by a reload-unload sequence ( $r$ ght) conducted on an aluminum single orystal [6]. 


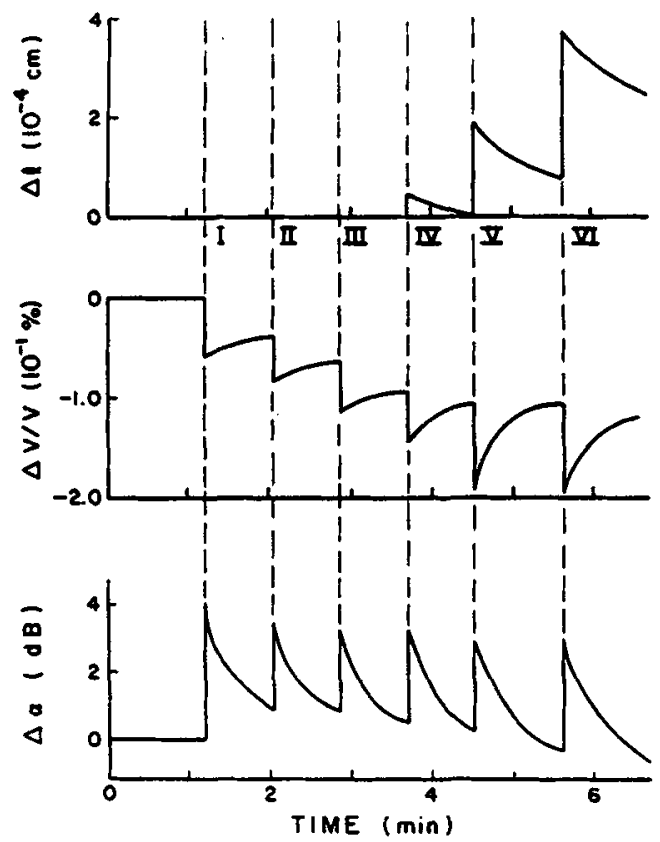

Fig. 4 - Data obtained from an aluminum single crystal subjected to high-power ultrasonio Insonation at a constant power level for different time periods [7]. $\Delta l=$ change in speoimen length

$\Delta v / v=$ relative ohange in ultrasonic velocity

$\Delta \alpha=$ change in ultrasonic attenuation

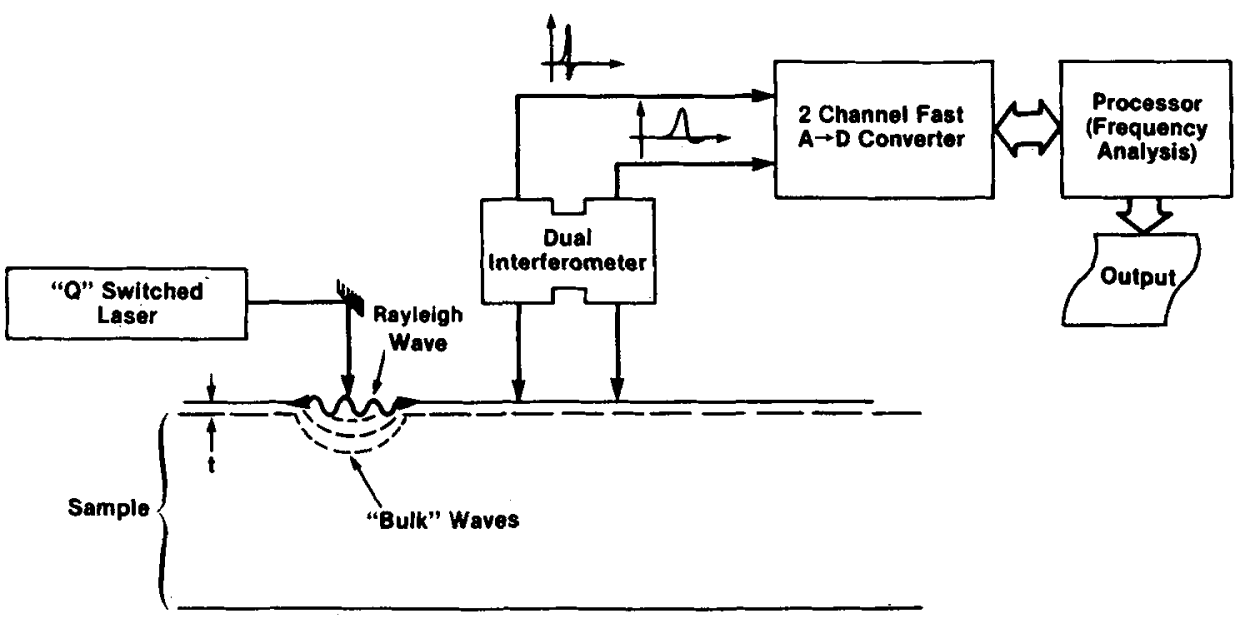

Fig. 5 - Laser beam generation and dual laser beam interferometric detection systea for making non-contact measurements of ultrasonio waves in surface layers of materials [17]. 
C10-834

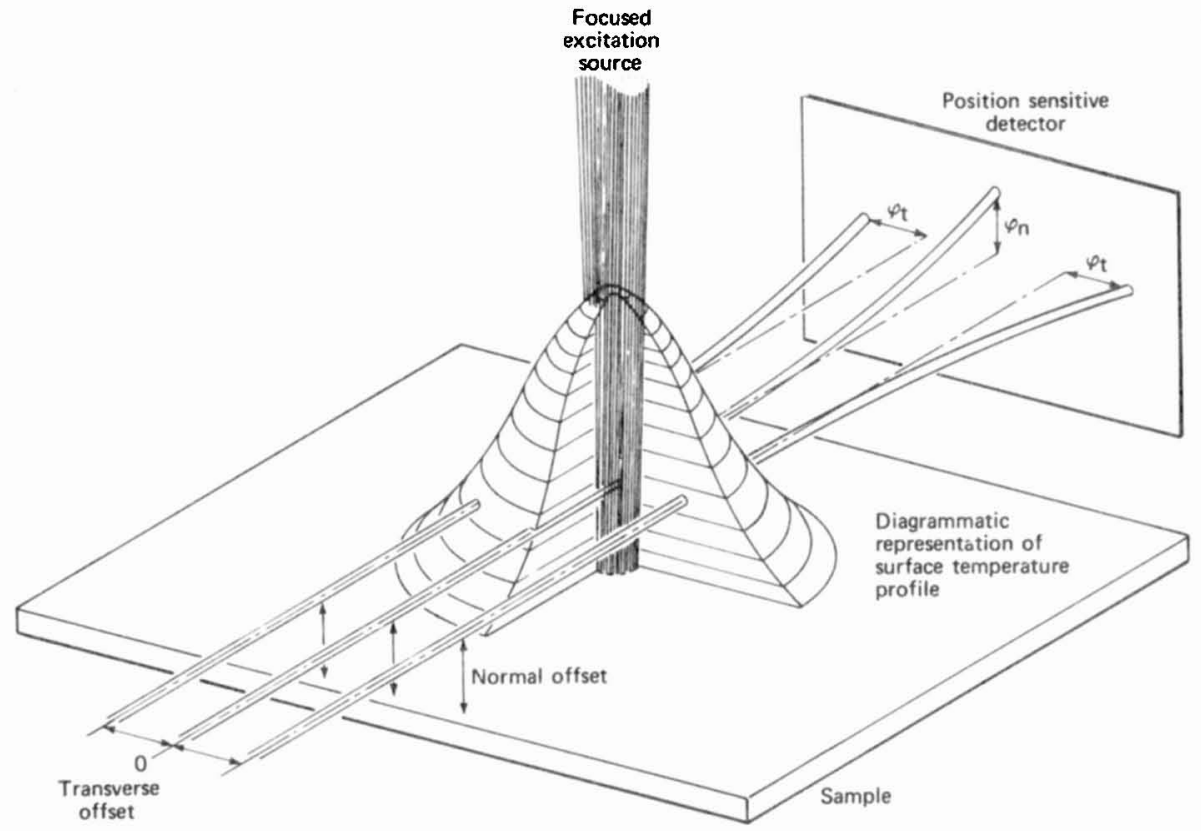

F1g. 6 - Schematic of thermal wave imaging technique using the "mirage effect" [18].

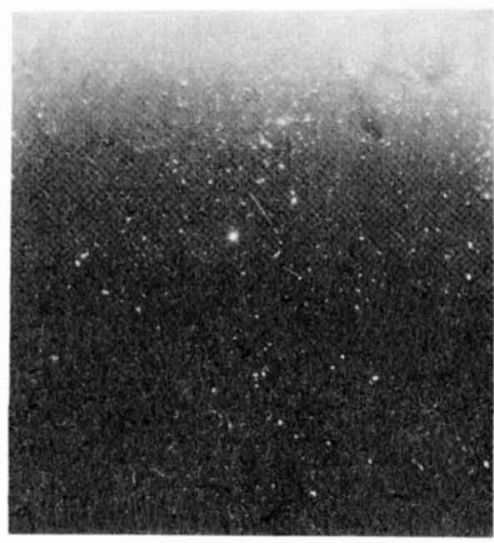

SECONDARY ELECTRON IMAGE

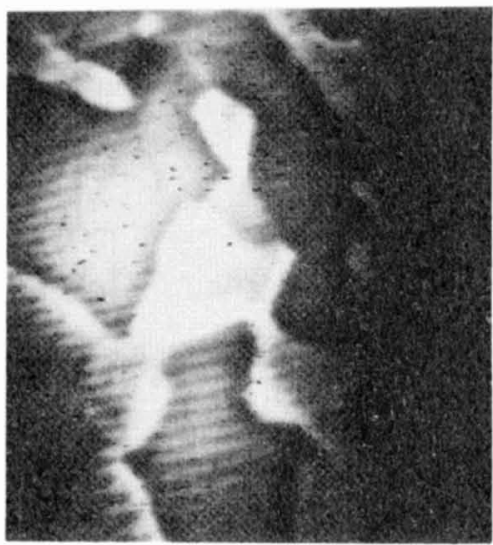

ACOUSTIC MAGNITUDE IMAGE

F18. T - Comparison of conventional scanning electron microscope inage of high purity polyorystalline aluminum sheet with electron-acoustic image [19]. 